\title{
Tackling the economic burden of postsurgical complications: would perioperative goal-directed fluid therapy help?
}

\author{
Gerard R Manecke ${ }^{1}$, Angela Asemota ${ }^{2}$ and Frederic Michard ${ }^{3 *}$
}

\begin{abstract}
Introduction: Pay-for-performance programs and economic constraints call for solutions to improve the quality of health care without increasing costs. Many studies have shown decreased morbidity in major surgery when perioperative goal directed fluid therapy (GDFT) is used. We assessed the clinical and economic burden of postsurgical complications in the University HealthSystem Consortium (UHC) in order to predict potential savings with GDFT.
\end{abstract}

Methods: Data from adults who had a major surgical procedure in 2011 were screened in the UHC database. Thirteen post-surgical complications were tabulated. In-hospital mortality, hospital length of stay and costs from patients with and without complications were compared. The risk ratios reported by the most recent meta-analysis were used to estimate the potential reduction in post-surgical morbidity with GDFT. Potential cost-savings were calculated from the actual and anticipated morbidity rates.

Results: A total of 75,140 patients met the search criteria, and 8,421 patients developed one or more post-surgical complications (morbidity rate 11.2\%). In patients with and without complications, in-hospital mortality was $12.4 \%$ and $1.4 \%(P<0.001)$, mean hospital length of stay was $20.5 \pm 20.1$ days and $8.1 \pm 7.1$ days $(P<0.001)$ and mean direct costs were $\$ 47,284 \pm 49,170$ and $\$ 17,408 \pm 15,612(P<0.001)$, respectively. With GDFT, morbidity rate was projected to decrease to 8.0 - 9.3\%, yielding gross costs savings of $\$ 43 \mathrm{M}-\$ 73 \mathrm{M}$ for the study population or $\$ 569-\$ 970$ per patient.

Conclusion: Postsurgical complications have a dramatic impact (+172\%) on costs. Potential costs savings resulting from GDFT are substantial. Perioperative GDFT may be recommended not only to improve quality of care but also to decrease costs.

\section{Introduction}

Pay-for-performance programs and economic constraints call for solutions improving the quality of health care without increasing costs [1]. In this respect, the American Society of Anesthesiology is developing a perioperative surgical home program in order to optimize quality and continuity of care for surgical patients [2,3]. Perioperative goal directed fluid therapy (GDFT) is a general term referring to targeted hemodynamic and fluid management using parameters such as stroke volume, cardiac output, and/or oxygen delivery, in conjunction with standard vital signs in managing patients during and immediately after surgery. Many studies have shown decreased morbidity in

\footnotetext{
* Correspondence: frederic_michard@edwards.com

${ }^{3}$ Global Medical Strategy, Critical Care, Edwards Lifesciences, Irvine, CA, USA Full list of author information is available at the end of the article
}

major surgery when GDFT is used [4,5] and it is now recommended by the National Health Service in the UK [6], by the French Society of Anesthesiology [7], and by the Enhanced Recovery After Surgery (ERAS) society in Europe [8]. Despite this, adoption of GDFT in the United States is poor $[9,10]$. Perioperative GDFT may require the use of hemodynamic monitoring equipment, such as minimally invasive cardiac output monitoring, beyond that used for simple, routine surgery. The cost of monitoring equipment for GDFT may be a barrier to adoption.

By reducing complication rates, GDFT would be expected to decrease cost [11]. Indeed, a favorable financial impact of GDFT resulting from reduction of complication rates has been reported [12,13]. These studies, however, are not current, and involved the use of the pulmonary artery catheter for monitoring. With the exception of cardiac 
surgery and liver transplantation, the pulmonary artery catheter is no longer commonly used for perioperative hemodynamic optimization, having been replaced by less invasive technologies. To date there have been no reports of large, randomized, controlled trials assessing the financial impact of GDFT.

The University HealthSystem Consortium (UHC) is an alliance of 120 academic medical centers and 300 of their affiliated hospitals [14]. Query of their database allows the determination of complications and costs of care in surgical patients. These data, in conjunction with the outcome impact of GDFT that has been reported in the medical literature, allows an estimation of potential GDFT-related cost-savings in major surgery in the UHC. The goal of our study was twofold: to describe the clinical and economic burden of postsurgical complications in the UHC, and to predict the economic impact of GDFT implementation.

\section{Materials and methods}

De-identified data from all adults who had major noncardiac surgery in 2011 were screened in the UHC database. Permission to perform and report the results of this study was provided by the University of California San Diego Human Research Protections Program. This committee waived the need for informed consent, since this was a database study.

\section{Patient selection}

Ten major surgical procedures were selected based on previous studies showing GDFT-associated positive outcomes [15-29]. Corresponding ICD9 codes were used to search specific procedures in the UHC database (Table 1). Because GDFT has thus far been shown to be effective only in adults, a restriction was used ensuring that only adult ( $\geq 18$ years old) patients were queried.

\section{Clinical data collection}

In-hospital postoperative complications queried, as defined by the UHC, included postoperative stroke, gastrointestinal hemorrhage, catheter-associated urinary tract infection, reopening of surgical site, acute myocardial infarction, coma or stupor, nosocomial pneumonia, wound infection, sepsis, pulmonary embolism or deep venous thrombosis, respiratory failure, hematoma and wound dehiscence. Morbidity rate was defined as the proportion of patients developing at least one complication during their hospital stay. Patients were sorted into two groups: those with complications and those without. For each group, in-hospital mortality and hospital length of stay (mean \pm SD) were extracted from the UHC database and compared.

\section{Cost data collection and cost-savings projection}

Direct costs (mean $\pm \mathrm{SD}$ ) related to the in-hospital treatment of patients with and without complications were obtained from the UHC database and compared. Direct costs are those associated with the actual procedures, they do not include overheads and wages for healthcare personnel. The most recent GDFT meta-analysis was used to estimate the potential reduction of postoperative morbidity from GDFT [5]. This meta-analysis reported an average odds ratio of 0.77 with a confidence interval ranging from 0.71 to 0.83 . Potential cost-savings were determined by using the projected number of patients developing one or more complication and the estimated related costs. This analysis was performed for the entire cohort, as well as for each surgical procedure. The analysis assumes complete, new implementation of GDFT.

Table 1 Ten major surgical procedures queried in the UHC database, corresponding ICD9 codes, and studies showing morbidity reduction with GDFT

\begin{tabular}{|c|c|c|}
\hline Surgical procedure & ICD9 codes & Author (reference) \\
\hline Abdominal aortic aneurysm open repair & 38.44 & Benes [15], Kuper [19], Lobo [20], Pearse [22], Wilson [29] \\
\hline Aorto-iliac and peripheral bypass & $39.25,39.29$ & Bisgaard [16], Kuper [19], Pearse [22], Wilson [29] \\
\hline Esophagectomy & $42.40,42.41,42.42$ & Boyd [17], Kuper [19], Lobo [20], Pearse [22], Wilson [29] \\
\hline Gastrectomy & $43.5,43.6,43.7,43.81,43.89,43.91,43.99$ & Boyd [17], Kuper [19], Lobo [20], Pearse [22], Wilson [29] \\
\hline Colectomy & $45.71-45.76,45.79,45.81-45.83$ & $\begin{array}{c}\text { Benes [15], Gan [18], Kuper [19], Noblett [21], Pearse [22], } \\
\text { Ramsingh [24], Wakeling [28] }\end{array}$ \\
\hline Resection of rectum & $48.40,48.43,48.49-48-52,48.59,48.61-48.65,48.69$ & $\begin{array}{c}\text { Benes [15], Gan [18], Kuper [19], Noblett [21], Pearse [22], } \\
\text { Ramsingh [24], Wakeling [28], Wilson [29] }\end{array}$ \\
\hline Hepatectomy & $50.22,50.3$ & Pearse [22], Ueno [26], \\
\hline Pancreatectomy & $52.51-52.53,52.59,52.6,52.7$ & Benes [15], Lobo [20], Ramsingh [24] \\
\hline Total cystectomy & $57.71,57.79$ & $\begin{array}{c}\text { Boyd [17], Gan [18], Kuper [19], Pearse [22], Pillai [23], } \\
\text { Ramsingh [24], Wilson [29] }\end{array}$ \\
\hline Femur \& hip fracture repair & $79.15,79.25,79.35,79.85,79.95$ & Kuper [19], Sinclair [25], Venn [27] \\
\hline
\end{tabular}

UHC, University HealthSystem Consortium; GDFT, goal directed fluid therapy. 


\section{Statistical analysis}

In-hospital mortality, hospital length of stay and costs were compared between patients with and without complications. Mortality rates (\%) were compared with the chi-square test, hospital length of stay (mean \pm SD) and costs (mean $\pm \mathrm{SD}$ ) were compared with the two-sample $t$-test with unequal variance.

\section{Results}

A total of 75,140 patients from 222 medical centers met the search criteria. Numbers of patients per surgery group are reported in Table 2. 8,421 patients developed one or more of the 13 postsurgical complications extracted from the database (morbidity rate 11.2\%). The most common postsurgical complication was wound infection $(4.0 \%)$, followed by sepsis $(1.8 \%)$, nosocomial pneumonia (1.7\%), reopening of surgical site (1.6\%), pulmonary embolism or deep venous thrombosis (1.5\%), and respiratory failure (1.4\%). All other complication rates were less than $1 \%$ (Figure 1). Morbidity rates for each surgery group are presented in Table 2.

\section{Clinical impact of postsurgical complications}

In patients with one or more complications and in patients without any complication in-hospital mortality was $12.4 \%$ and $1.4 \%$ (difference $11.0 \%, P<0.001$ ), and mean hospital length of stay was $20.5 \pm 20.1$ and $8.1 \pm 7.1$ days (difference 12.4 days, $P<0.001$ ), respectively. The impact of postsurgical complications on in-hospital mortality and hospital length of stay for each surgery group is presented in Table 2.

\section{Economic impact of postsurgical complications}

Average direct cost was $\$ 47,284 \pm 49,170$ and $\$ 17,408 \pm$ 15,612 (difference $\$ 29,876, P<0.001$ ) per patient with one or more complications and per patient with no complications, respectively. Thus, in 2011 the UHC spent a total of $\$ 252 \mathrm{M}(\$ 29,876 \times 8,421$ patients $)$ to treat postsurgical complications in the study population. The economic impact of postsurgical complications for each surgery group is presented in Table 2 .

\section{Projected cost-savings with implementation of GDFT}

The projected number of patients developing one or more complication, assuming an odds ratio ranging between 0.71 and 0.83 , was 5,979 to 6,989 (morbidity rate 8.0 to $9.3 \%$, Figure 2). Thus, after implementation of GDFT, projected gross savings would be $\$ 569$ to $\$ 970$ per patient and $\$ 43$ to $73 \mathrm{M}$ for the entire UHC study population (Figure 2). Projected cost savings for each surgery group are presented in Figures 3 and 4.

\section{Discussion}

In our large UHC patient population, the occurrence of one or more postsurgical complications had a dramatic impact on in-hospital mortality (multiplied by 9.0 ) and hospital length of stay (multiplied by 2.5). Although impressive, these findings are consistent with the results of a recent study [30] done in 34,256 surgical patients discharged from a nonprofit 12-hospital system in the southern US. In that study, in-hospital mortality was 21fold greater (12.3 versus $0.6 \%$ ) and hospital length of stay was 4.7-fold greater in patients who developed one or more postsurgical complications.

Postsurgical complications also had a very significant impact on costs $(+172 \%)$, the extra costs for treating patients developing one or more complications exceeding by far the cost of the surgical procedure itself $(\$ 29,876$ versus $\$ 17,408)$. Our cost findings are consistent with previous and smaller studies. In 1,200 patients undergoing

Table 2 Clinical and economic characteristics of the study population

\begin{tabular}{|c|c|c|c|c|c|c|c|c|}
\hline \multirow[t]{3}{*}{ Surgery } & \multirow[t]{3}{*}{ Patients, n } & \multirow[t]{3}{*}{ Morbidity, \% } & \multirow{2}{*}{\multicolumn{2}{|c|}{ Mortality, \% }} & \multirow{2}{*}{\multicolumn{2}{|c|}{$\frac{\text { HLOS, days }}{\text { (mean } \pm \text { SD) }}$}} & \multirow{2}{*}{\multicolumn{2}{|c|}{$\begin{array}{l}\text { Direct cost, \$ } \\
\text { (mean } \pm \text { SD) }\end{array}$}} \\
\hline & & & & & & & & \\
\hline & & & With & Without & With & Without & With & Without \\
\hline AAA open repair & 2,040 & 19.6 & 20.8 & 6.0 & $23.9 \pm 17.2$ & $10.3 \pm 8.2$ & $76,169 \pm 55,530$ & $30,451 \pm 24,023$ \\
\hline Vascular bypass & 6,765 & 9.5 & 10.3 & 1.1 & $17.5 \pm 15.2$ & $7.3 \pm 6.5$ & $42,202 \pm 39,618$ & $16,790 \pm 12,601$ \\
\hline Esophagectomy & 1,794 & 12.5 & 6.3 & 2.4 & $23.2 \pm 15.5$ & $13.1 \pm 11.7$ & $59,382 \pm 48,850$ & $32,457 \pm 30,571$ \\
\hline Gastrectomy & 5,995 & 8.7 & 11.7 & 1.0 & $25.0 \pm 21.9$ & $6.8 \pm 7.7$ & $54,879 \pm 45,868$ & $16,159 \pm 15,986$ \\
\hline Colectomy & 19,055 & 16.0 & 15.2 & 2.6 & $23.1 \pm 25.2$ & $9.6 \pm 8.2$ & $49,160 \pm 56,975$ & $17,158 \pm 16,481$ \\
\hline Resection of rectum & 4,251 & 9.2 & 4.9 & 0.4 & $16.2 \pm 13.0$ & $7.1 \pm 5.3$ & $29,874 \pm 27,882$ & $13,723 \pm 10,020$ \\
\hline Hepatectomy & 4,934 & 7.6 & 14.8 & 0.7 & $17.9 \pm 16.6$ & $6.3 \pm 4.4$ & $48,961 \pm 50,382$ & $16,501 \pm 12,080$ \\
\hline Pancreatectomy & 6,564 & 14.6 & 11.4 & 0.4 & $21.7 \pm 19.1$ & $9.7 \pm 6.9$ & $53,217 \pm 50,882$ & $20,888 \pm 15,390$ \\
\hline Cystectomy & 4,036 & 10.9 & 5.2 & 0.4 & $19.3 \pm 13.0$ & $9.1 \pm 5.4$ & $43,598 \pm 34,224$ & $20,669 \pm 10,511$ \\
\hline F\&H fracture repair & 19,706 & 7.3 & 10.6 & 0.9 & $14.6 \pm 12.2$ & $6.6 \pm 5.9$ & $33,890 \pm 33,115$ & $14,919 \pm 13,575$ \\
\hline
\end{tabular}

In-hospital mortality, hospital length of stay (HLOS) and direct costs were compared between patients with one or more complications (With) and patients without any complication (Without). All comparisons were statistically significant with a $P$-value $<0.001$. AAA, abdominal aortic aneurysm; F\&H, femur and hip. 


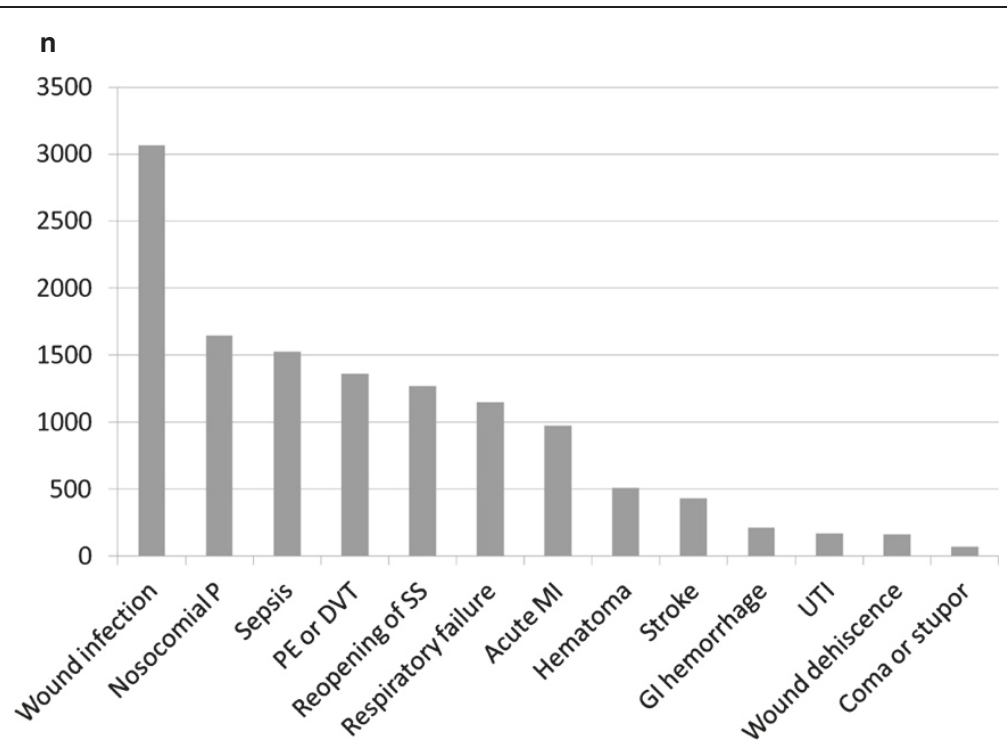

Figure 1 Type ( $x$ axis) and number (y axis) of postoperative complications queried in the study population $(75,140$ patients). $P$, pneumonia; SS, surgical site; PE, pulmonary embolism; DVT, deep venous thrombosis; Ml, myocardial infarction; Gl, gastro-intestinal; UTI, catheter-associated urinary tract infection.

major abdominal surgery, Vonlanthen et al. [31] showed that patients with an uneventful course had mean costs per case of $\$ 27,946$, whereas patients with one or more complications had a mean cost per case $\$ 34,446$ higher. In 2,250 patients undergoing general and vascular surgery, Boltz et al. [32] showed that for patients developing one, two, and three or more complications the excess costs were $\$ 6,358, \$ 12,802$ and $\$ 42,790$, respectively. In the above mentioned 34,256-patient cohort study [30], including major and minor procedures (for example, appendectomy), the average cost difference between a patient with and without complications was $\$ 22,398$. These findings demonstrate the dramatic impact of complications on hospital costs and highlight a relevant savings capacity for major surgical procedures.

In our study, potential cost savings related to the use of GDFT were substantial, with projected gross savings of $\$ 569$ to $\$ 970$ per patient treated. This analysis revealed that potential savings per patient depend on the surgical procedure, ranging from $\$ 235$ to $\$ 402$ for femur and hip fracture to $\$ 1,523$ to $\$ 2,599$ for abdominal aortic aneurysm open surgery (Figure 3 ). Given the volume of
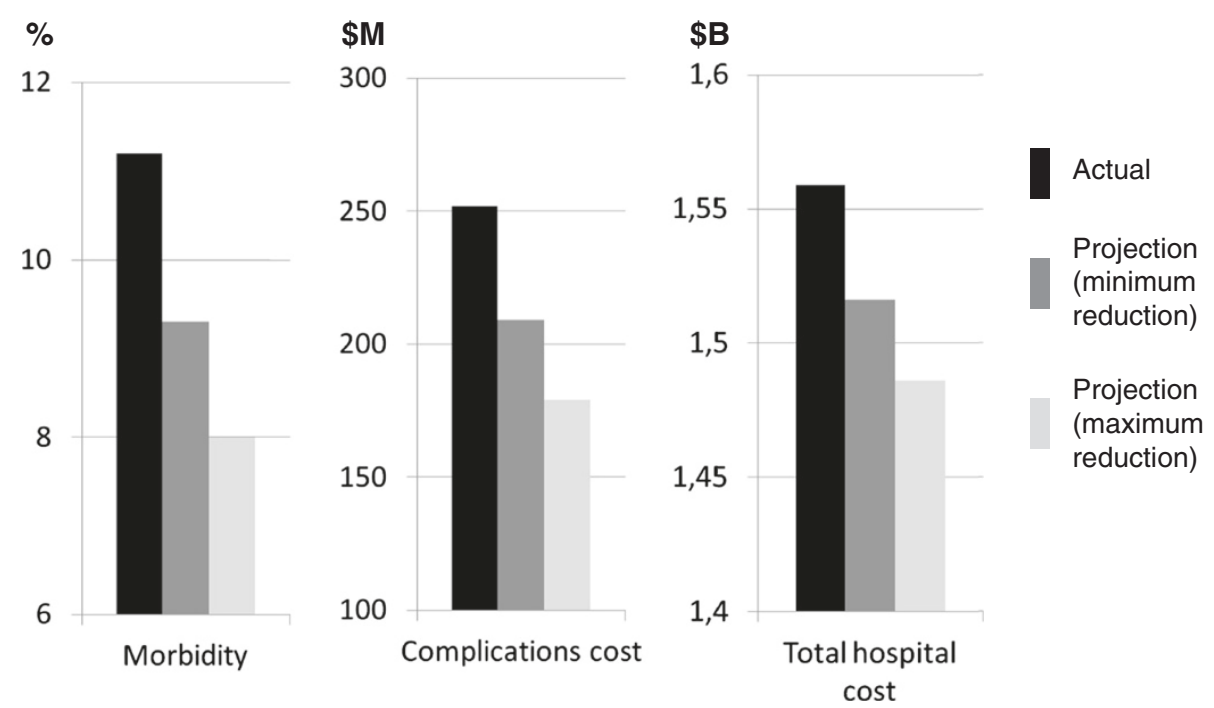

Figure 2 Actual and projected morbidity rates, complication costs and total hospital costs with goal-directed fluid therapy implementation. 


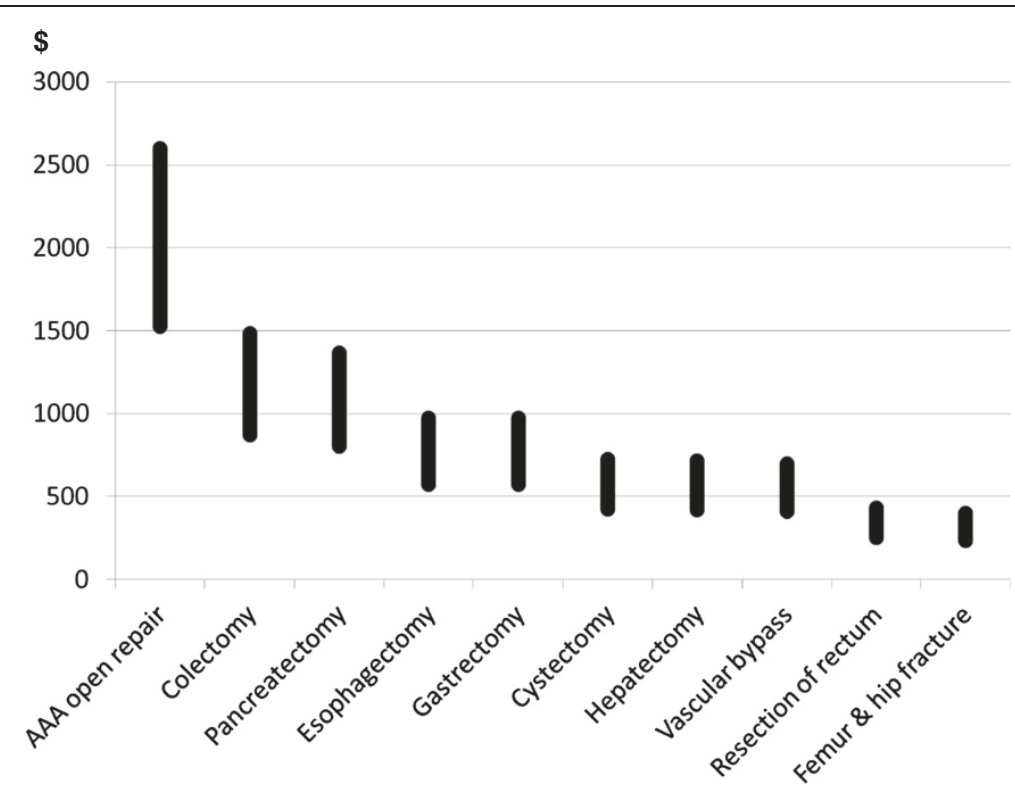

Figure 3 Projected cost-savings per patient with perioperative goal-directed fluid therapy. Each vertical black bar represents the range between minimum and maximum savings. AAA, abdominal aortic aneurysm.

procedures, total savings for UHC were the most significant ( $\$ 16.6 \mathrm{M}$ to $28.3 \mathrm{M}$ ) for colectomy (Figure 4$)$. Our cost-saving estimations are lower than those reported by a previous UK prospective trial [13] showing a cost reduction of $£ 1259$ (\$1889) per patient, and much lower than another trial [12] reporting $£ 3467$ (\$5201) costsavings per patient when GDFT was used. As far as we know, these are the only two prospective studies thus far comparing the cost for treating surgical patients with and without GDFT. These single-center evaluations have been done in a limited number of patients monitored with a pulmonary artery catheter 14 and 20 years ago in UK hospitals. Anesthesia and surgical practices, as well as healthcare costs, have dramatically changed over the last decades, rendering their applicability to current practices in the US questionable. We provide in this article

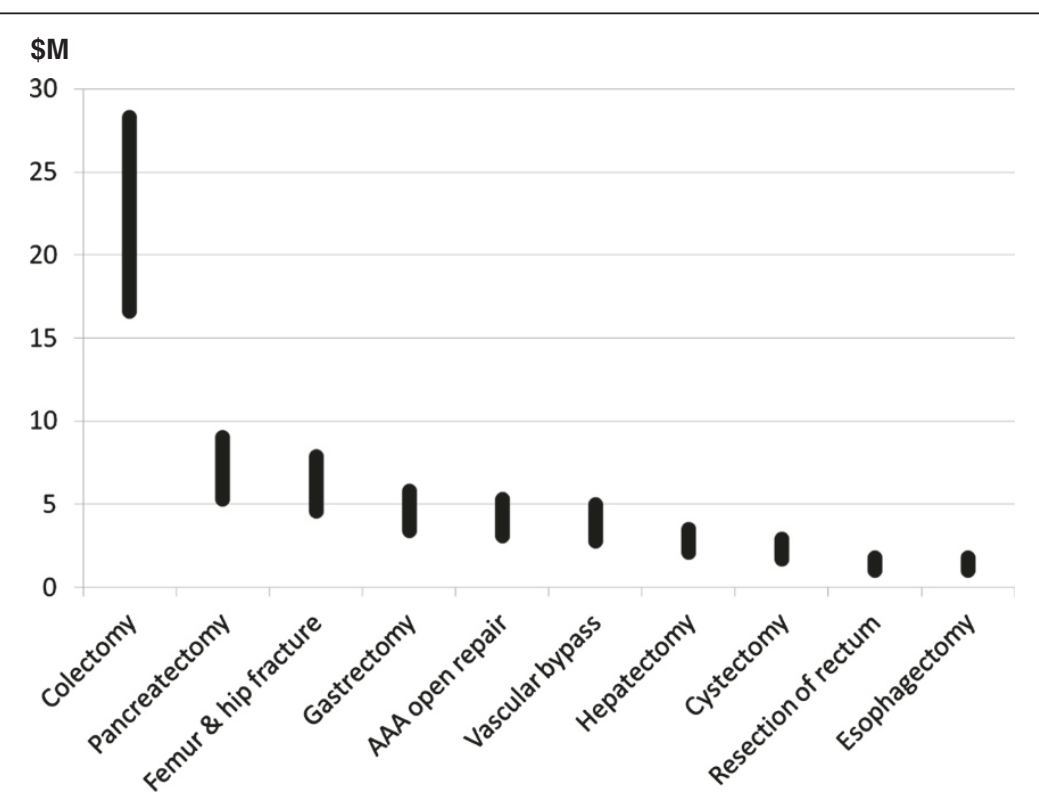

Figure 4 Projected total cost-savings for the University HospitalSystem Consortium study population with perioperative goal directed fluid therapy. Each vertical black bar represents the range between minimum and maximum savings. 
a cost-saving estimation based on the most recent GDFT meta-analysis and a very large number of patients. This is the first clinical and economic prediction of its kind based on real US data. Our estimations are also lower than a recent cost simulation done in Sweden and suggesting that $€ 1882 /$ patient (\$2258) could be saved if GDFT was to become the new standard of care in elderly patients with hip fracture [33].

Although free solutions have been proposed for GDFT [34], cardiac output monitoring techniques such as transesophageal Doppler and arterial-pulse contour methods are often used [35]. The cost of these technologies varies a lot from one region to the other (depending on reimbursement policies) and from one hospital to the other (depending on the volume of products used or bought every year by hospitals or group purchasers, respectively). If one assumes the cost of GDFT technologies, including capital investment for hemodynamic monitors and disposable sensors, to be approximately $\$ 300 /$ patient in the US, the net savings are projected to be $\$ 269$ to $\$ 670$ per treated patient. When considering the implementation of GDFT, potential additional costs related to staff training and change in fluid or/and drug usage may also be considered. Training and technical support are usually provided (at least in part) by cardiac output monitoring companies, the use of vasoactive and inotropic drugs is not part of most recent GDFT guidelines [6-8], and recent clinical studies have shown that the net effect of GDFT strategies is usually no change [5] if not a decrease [36] in the total amount of fluid administered to patients during the perioperative period. However, GDFT costs may significantly vary from one medical center to the other, depending on the hemodynamic parameter used for GDFT (pulse pressure variation versus stroke volume), the cardiac output monitor amortization (large volume versus low volume of surgery), and the fluid used (albumin versus crystalloid). Therefore, another way to look at our data is to consider the potential savings of $\$ 569$ to $\$ 970 /$ patient as the upper limit for all GDFT-related costs. Then, a fair evaluation of the potential savings can be made on a case by case basis.

Our analysis probably underestimates the potential scope of the financial benefit of GDFT for several reasons. First, the analysis was strictly limited to major surgery in which outcome has already conclusively been shown to be improved by the use of GDFT. There are other types of surgery, such as major orthopedic spine, solid organ transplantation, and major gynecologic surgery, in which this approach would likely be associated with fewer complications $[6,19]$. Second, the UHC database, being an administrative database, has the advantage of containing reliable financial information, but also the disadvantage of underestimating the real incidence of postsurgical complications. In a comparison study,
Steinberg et al. [37] reported a 28\% morbidity rate with the National Surgical Quality Improvement Program (NSQIP) database (a clinical database specifically designed to collect up to 21 complications) and an $11 \%$ morbidity rate with the UHC database in the same surgical population. In the same study [37], the incidence of wound infection was $13 \%$ and only $1 \%$ with the NSQIP and the UHC database, respectively. Third, we used the odds ratio reported by the most recent GDFT metaanalysis [5] to estimate the potential reduction of postoperative morbidity. Because quality of care has improved over time, results of meta-analysis may be questioned because they include studies done a long time ago. A metaanalysis published in 2011 [4] looked specifically at the effects of GDFT over time. Interestingly, the morbidity reduction with GDFT was observed similarly for studies published in the 1980s, the 1990s and after 2000. The odds ratio for studies published after 2000 was 0.38 (0.29 to 0.50 ). If we had used this odd ratio, the projected savings would have been almost two times greater than those we report in the present study. Finally, our estimation does not take into account costs related to hospital readmissions. Postsurgical complications are the main cause for hospital readmission and it has been recently suggested that reducing complications may be the most efficient way to decrease readmissions and related costs [38].

Our analysis was limited to academic centers. The savings per patient may be different when the private sector is considered, and the total potential savings to the US healthcare system would be considerably more if the private sector was to be included. The potential clinical benefits and hence cost savings were derived from a meta-analysis, which could have incorporated reporting bias, with positive studies more likely to have been published. We considered the same postsurgical morbidity reduction with GDFT for all surgical procedures. Although previous meta-analyses [4,5] did not find any interaction between the type of surgery and the effect of GDFT, this may not always be true. Also patients with co-morbidities may benefit more from GDFT, but this is not something we were able to study. In addition, the assumption was made that there was no GDFT being used in 2011, whereas a survey published the same year indicates that approximately 5\% of US anesthesiologists consistently use GDFT for high-risk surgery [9]. Further, this study assumes complete implementation of GDFT, which may be an unrealistic goal. The study by Kuper et al. [19] is the only real-life and large-scale GDFT implementation experience we know. They reported an adoption rate of $65 \%$. Assuming a comparable adoption rate, our projected savings would have ranged between $\$ 370$ and $\$ 631$ per patient. Finally, if costs and savings are of utmost importance for payers, profits (reimbursement - cost) are even more important for hospitals [30]. 
We did not have access to reimbursement information so that we were unable to project the impact of GDFT on hospital profits. Prospective studies are definitely required to assess the impact of GDFT implementation not only on costs but also on hospital profits since this may become the main driver for hospital adoption.

\section{Conclusion}

Our study demonstrates the dramatic impact of postsurgical complications on costs $(+172 \%)$ in patients undergoing major surgical procedures at UHC hospitals, and suggests significant savings if GDFT was to be implemented. Projected cost-savings per patient are the highest for open repair of abdominal aortic aneurysm. However, taking into account the volume of surgery, the highest total savings for the UHC are expected to come from the implementation of GDFT in colectomy. Outside the UHC system, cost-savings are necessarily institution-specific, depending upon local case mix, morbidity rates, surgical costs and GDFT-related costs. Individual institutions can use our methodology, on a local level, in their decision to pilot and implement GDFT. Finally, we believe this analysis provides the necessary data to warrant a large and prospective study on the economic impact of GDFT.

\section{Key messages}

- We assessed the costs of postsurgical complications in 75,140 patients undergoing 10 major abdominal, orthopedic, vascular and urologic surgical procedures in order to predict potential savings with perioperative goal-directed fluid therapy (GDFT)

- Postsurgical complications were responsible for a $172 \%$ increase in hospital costs (from $\$ 17,408$ to $\$ 47,284$ per patient)

- Projected cost-savings with the implementation of perioperative GDFT ranged between $\$ 569$ and \$970 per patient

- Highest cost-savings per patient $(\$ 1,523$ to $\$ 2,599)$ were expected to come from the implementation of GDFT for open repair of abdominal aortic aneurysm.

- Given the volume of surgery, highest savings for the entire study population ( $\$ 16.6 \mathrm{M}$ to $28.3 \mathrm{M}$ ) were expected to come from the implementation of GDFT in patients undergoing colectomy

\section{Abbreviations}

GDFT: goal-directed fluid therapy; UHC: University HealthSystem Consortium.

\section{Competing interests}

GRM received travel expense reimbursements and speaking fees from Edwards Lifesciences and FM is an employee of Edwards Lifesciences. However this manuscript does not support the use of any specific medical device. AA declares that she has no competing interests.

\section{Authors' contributions}

GRM contributed to the design of the work; the acquisition, analysis, and interpretation of data for the work; drafting the work and revising it critically for important intellectual content; and final approval of the version to be published. AA contributed to the acquisition of data for the work; drafting the work; and final approval of the version to be published. FM contributed to the conception of the work; the analysis, and interpretation of data for the work; revising the work critically for important intellectual content; and final approval of the version to be published. All authors read and approved the final manuscript.

\section{Author details}

'University of California San Diego, UCSD Medical Center, 200 West Arbor Drive, San Diego, CA 92103, USA. ${ }^{2}$ University of California San Diego School of Medicine, 200 West Arbor Drive, San Diego, CA 92103, USA. ${ }^{3}$ Global Medical Strategy, Critical Care, Edwards Lifesciences, Irvine, CA, USA.

Received: 10 February 2014 Accepted: 1 October 2014

Published online: 11 October 2014

\section{References}

1. Birkmeyer NJO, Birkmeyer JD: Strategies for improving surgical quality: should payers reward excellence or efforts? N Engl J Med 2006, 354:864-870.

2. Vetter TR, Ivankova NV, Goeddel LA, McGwin G Jr, Pittet JF: An analysis of methodologies that can be used to validate if a Perioperative Surgical Home improves the patient-centeredness, evidence-based practice, quality, safety, and value of patient care. Anesthesiology 2013, 119:1261-1274.

3. Vetter TR, Goeddel LA, Boudreaux AM, Hunt TR, Jones KA, Pittet JF: The Perioperative Surgical Home: how can it make the case so everyone wins? BMC Anesthesiol 2013, 14:13-16.

4. Hamilton M, Cecconi M, Rhodes A: A systematic review and meta-analysis on the use of preemptive hemodynamic intervention to improve outcomes in moderate and high-risk surgery. Anesth Analg 2011, 112:1392-1402.

5. Pearse RM, Harrison DA, McDonald N, Gillies MA, Blunt M, Ackland G, Grocott MPW, Ahern A, Griggs K, Scott R, Hinds C, Rowan K: Effect of a perioperative, cardiac output-guided, hemodynamic therapy algorithm on outcomes following major gastrointestinal surgery: a randomized clinical trial and updated systematic review. JAMA 2014, 311:2181-2190.

6. Mythen MG, Swart M, Acheson N, Crawford R, Jones K, Kuper M, McGrath $J S$, Horgan A: Perioperative fluid management: consensus statement from the enhanced recovery partnership. Perioperat Med 2012, 1:2.

7. Vallet B, Blanloeil Y, Cholley B, Orliaguet G, Pierre S, Tavernier B: Guidelines for perioperative haemodynamic optimization. Ann Fr Anesth Reanim 2013, 32:454-462.

8. Gustafsson UO, Scott MJ, Schwenk W, Demartines N, Roulin D, Francis N, McNaught CE, MacFie J, Liberman AS, Soop M, Hill A, Kennedy RH, Lobo DN, Fearon K, Ljungqvist O: Guidelines for perioperative care in elective colonic surgery: enhanced recovery after surgery (ERAS) society. World J Surg 2013, 37:259-284.

9. Cannesson M, Pestel G, Ricks C, Hoeft A, Perel A: Hemodynamic monitoring and management in patients undergoing high risk surgery: a survey among North American and European anesthesiologists. Crit Care 2011, 15:R197.

10. Miller TE, Roche AM, Gan TJ: Poor adoption of hemodynamic optimization during major surgery: are we practicing substandard care? Anesth Analg 2011, 112:1274-1276.

11. Marx G, Michard F: Perioperative hemodynamic optimization: from clinical to economic benefits. In Annual Update of Intensive Care and Emergency Medicine. Edited by Vincent JL. Berlin: Springer Verlag; 2013:553-564.

12. Fenwick E, Wilson J, Sculpher M, Claxton K: Pre-operative optimisation employing dopexamine or adrenaline for patients undergoing major elective surgery: a cost-effectiveness analysis. Intensive Care Med 2002, 28:599-608.

13. Guest JF, Boyd O, Hart WM, Grounds RM, Bennett ED: A cost analysis of a treatment policy of a deliberate perioperative increase in oxygen delivery in high risk surgical patients. Intensive Care Med 1997, 23:85-90.

14. UHC [https://www.uhc.edu] 
15. Benes J, Chytra I, Altmann P, Hluchy M, Kasal E, Svitak R, Pradl R, Stepan M: Intraoperative fluid optimization using stroke volume variation in high risk surgical patients: results of prospective randomized study. Crit Care 2010, 14:R118

16. Bisgaard J, Gilsaa T, Ronholm E, Toft P: Haemodynamic optimisation in lower limb arterial surgery: room for improvement? Acta Anaesthesiol Scand 2013, 57:189-198.

17. Boyd O, Grounds RM, Bennett ED: A randomized clinical trial of the effect of deliberate perioperative increase of oxygen delivery on mortality in high-risk surgical patients. JAMA 1993, 270:2699-2707.

18. Gan TJ, Soppitt A, Maroof M, el-Moalem H, Robertson KM, Moretti E, Dwane P, Glass PS: Goal-directed intraoperative fluid administration reduces length of hospital stay after major surgery. Anesthesiology 2002, 97:820-826.

19. Kuper M, Gold SJ, Callow C, Quraishi T, King S, Mulreany A, Biachi M, Conway DH: Intraoperative fluid management guided by oesophageal Doppler monitoring. BMJ 2011, 342:d3016.

20. Lobo SMA, Salgado PF, Castillo VGT, Borim AA, Polachini CA, Palchetti JC, Brienzi SLA, de Oliveira GG: Effects of maximizing oxygen delivery on morbidity and mortality in high-risk surgcial patients. Crit Care Med 2000, 28:3396-3404.

21. Noblett SE, Snowden CP, Shenton BK, Horgan AF: Randomized clinical trial assessing the effect of Doppler-optimized fluid management on outcome after elective colorectal resection. Br J Surg 2006, 93:1069-1076.

22. Pearse R, Dawson D, Fawcett J, Rhodes A, Grounds RM, Bennett ED: Early goal-directed therapy after major surgery reduces complications and duration of hospital stay. A randomised, controlled trial [ISRCTN38797445]. Crit Care 2005, 9:R687-R693.

23. Pillai P, McEleavy I, Gaughan M, Snowden C, Nesbitt I, Durkan G, Johnson M, Cosgrove J, Thorpe A: A double-blind randomized controlled clinical trial to assess the effect of Doppler optimized intraoperative fluid management on outcome following radical cystectomy. J Urol 2011, 186:2201-2206

24. Ramsingh DS, Sanghvi C, Gamboa J, Cannesson M, Applegate RL 2nd: Outcome impact of goal directed fluid therapy during high risk abdominal surgery in low to moderate risk patients: a randomized controlled trial. J Clin Monit Comput 2013, 27:249-257.

25. Sinclair S, James S, Singer M: Intraoperative intravascular volume optimisation and length of hospital stay after repair of proximal femoral fracture: randomised controlled trial. BMJ 1997, 315:909-912.

26. Ueno S, Tanabe G, Yamada H, Kusano C, Yoshidome S, Nuruki K, Yamamoto S, Aikou T: Response of patients with cirrhosis who have undergone partial hepatectomy to treatment aimed at achieving supranormal oxygen delivery and consumption. Surgery 1998, 123:278-286.

27. Venn R, Steele A, Richardson P, Poloniecki J, Grounds M, Newman P: Randomized controlled trial to investigate influence of the fluid challenge on duration of hospital stay and perioperative morbidity in patients with hip fractures. Br J Anaesth 2002, 88:65-71.

28. Wakeling HG, McFall MR, Jenkins CS, Woods WG, Miles WF, Barclay GR, Fleming SC: Intraoperative oesophageal Doppler guided fluid management shortens postoperative hospital stay after major bowel surgery. Br J Anaesth 2005, 95:634-642.

29. Wilson J, Woods I, Fawcett J, Whall R, Dibb W, Morris C, McManus E: Reducing the risk of major elective surgery: randomised controlled trial of preoperative optimisation of oxygen delivery. BMJ 1999, 318:1099-1103.

30. Eappen S, Lane BH, Rosenberg B, Lipsitz SA, SAdoff D, Matheson D, Berry WR, Lester M, Gawande AA: Relationship between occurrence of surgical complications and hospital finances. JAMA 2013, 309:1599-1606.

31. Vonlanthen R, Slankamenac K, Breitenstein S, Puhan MA, Muller MK, Hahnloser D, Hauri D, Graf R, Clavien PA: The impact of complications on costs of major surgical procedures: a cost analysis of 1200 patients. Ann Surg 2011, 254:907-913.

32. Boltz MM, Hollenbeak CS, Ortenzi G, Dillon PW: Synergistic implications of multiple postoperative outcomes. Am J Med Qual 2013, 27:383-390.

33. Bartha E, Davidson T, Hommel A, Thorngren KG, Carlsson P, Kalman S: Cost effectiveness analysis of goal-directed hemodynamic treatment of elderly hip fracture patients. Anesthesiology 2012, 117:519-530.

34. Lopes MR, Oliveira MA, Pereira VO, Lemos IP, Auler JO Jr, Michard F: Goal-directed fluid management based on pulse pressure variation monitoring during high risk surgery: a pilot randomized controlled trial. Crit Care 2007, 11:R100.

35. Pearse RM, Holt PJE, Grocott MPW: Managing perioperative risk in patients undergoing elective non-cardiac surgery. BMJ 2011, 343:d5759.

36. Miller TE, Thacker J, White WD, Mantyh C, Migaly J, Jin J, Roche AM, Eisenstein EL, Edwards R, Anstrom KJ, Moon RE, Gan TJ: Reduced length of hospital stay in colorectal surgery after implementation of an enhanced recovery protocol. Anesth Analg 2014, 118:1052-1061.

37. Steinberg SM, Popa MR, Michalek JA, Bethel MJ, Ellison EC: Comparison of risk adjustment methodologies in surgical quality improvement. Surgery 2008, 144:662-669.

38. Lawson EH, Hall BL, Louie R, Ettner SL, Zingmond DS, Han L, Rapp M, Ko CY: Association between occurrence of a postoperative complication and readmission. Ann Surg 2013, 258:10-18.

doi:10.1186/s13054-014-0566-1

Cite this article as: Manecke et al:: Tackling the economic burden of postsurgical complications: would perioperative goal-directed fluid therapy help? Critical Care 2014 18:566.

\section{Submit your next manuscript to BioMed Central and take full advantage of:}

- Convenient online submission

- Thorough peer review

- No space constraints or color figure charges

- Immediate publication on acceptance

- Inclusion in PubMed, CAS, Scopus and Google Scholar

- Research which is freely available for redistribution 